Kristýna Černá ${ }^{1}$

\title{
EXPOSURE TO AIRBORNE FUNGI DURING SORTING OF RECYCLABLE PLASTICS IN WASTE TREATMENT FACILITIES
}

\author{
${ }^{1}$ Czech University of Life Sciences Prague, Prague, Czech Republic \\ Faculty of Environmental Sciences, Department of Applied Ecology \\ ${ }^{2}$ Charles University in Prague, Prague, Czech Republic \\ Faculty of Science, Department of Botany \\ ${ }^{3}$ Academy of Sciences of Czech Republic, Průhonice, Czech Republic \\ Institute of Botany
}

\begin{abstract}
Background: In working environment of waste treatment facilities, employees are exposed to high concentrations of airborne microorganisms. Fungi constitute an essential part of them. This study aims at evaluating the diurnal variation in concentrations and species composition of the fungal contamination in 2 plastic waste sorting facilities in different seasons. Material and Methods: Air samples from the 2 sorting facilities were collected through the membrane filters method on 4 different types of cultivation media. Isolated fungi were classified to genera or species by using a light microscopy. Results: Overall, the highest concentrations of airborne fungi were recorded in summer $\left(9.1 \times 10^{3}-9.0 \times 10^{5}\right.$ colony-forming units $\left.(\mathrm{CFU}) / \mathrm{m}^{3}\right)$, while the lowest ones in winter $\left(2.7 \times 10^{3}-2.9 \times 10^{5} \mathrm{CFU} / \mathrm{m}^{3}\right)$. The concentration increased from the beginning of the work shift and reached a plateau after 6-7 h of the sorting. The most frequently isolated airborne fungi were those of the genera Penicillium and Aspergillus. The turnover of fungal species between seasons was relatively high as well as changes in the number of detected species, but potentially toxigenic and allergenic fungi were detected in both facilities during all seasons. Conclusions: Generally, high concentrations of airborne fungi were detected in the working environment of plastic waste sorting facilities, which raises the question of health risk taken by the employees. Based on our results, the use of protective equipment by employees is recommended and preventive measures should be introduced into the working environment of waste sorting facilities to reduce health risk for employees. Med Pr 2017;68(1):1-9
\end{abstract}

Key words: occupational exposure, airborne fungi, waste sorting facilities, plastic waste, potential health risk, identification of fungi

Corresponding author: Kristýna Černá, Czech University of Life Sciences Prague, Faculty of Environmental Sciences, Department of Applied Ecology, Kamýcká 129, 16521 Prague 6 - Suchdol, Czech Republic, e-mail: cernakristyna@fzp.czu.cz Received: June 11, 2016, accepted: September 22, 2016

\section{INTRODUCTION}

In many working environments of waste management, employees are exposed over long periods to high concentrations of airborne microorganisms. Many studies by different authors have recently pointed out health risks associated with such environments [1-3]. Waste sorting facilities represent one such working environment since waste in sorting facilities is frequently contaminated by organic residues that serve as a nutrient substrate to numerous microorganisms. Fungi make up an important part of these microorganisms and multitude of their mycelial fragments and other dispersal particles may be released during waste handling into the working environment [4].

In waste sorting facilities, high concentrations of airborne fungi were found varying within a wide range of values depending on the sampling site, sampling method and processing of samples $\left(1.9 \times 10^{3}-1.6 \times 10^{4}\right.$ colonyforming units $\left.(\mathrm{CFU}) / \mathrm{m}^{3}\right)$ [5], $0.8-2.4 \times 10^{4} \mathrm{CFU} / \mathrm{m}^{3}$ [4], $6.5 \times 10^{2}-2.5 \times 10^{4} \mathrm{CFU} / \mathrm{m}^{3}$ [6], $0.3-1.6 \times 10^{5} \mathrm{CFU} / \mathrm{m}^{3}$ [7], $\left.7.8 \times 10^{3}-2.3 \times 10^{5} \mathrm{CFU} / \mathrm{m}^{3}[8], 1.5 \times 10^{3}-2.9 \times 10^{5} \mathrm{CFU} / \mathrm{m}^{3}[9]\right)$. Generally, the high amounts of airborne fungi particles inhaled by employees in sorting facilities may result in

Funding: grant No. 4222013123163 entitled "Fungal contamination in working environment of selected waste sorting facilities" by Grant Agency of the Faculty of Environmental Sciences, Czech University of Life Sciences Prague. Project manager: Kristýna Černá, M.Sc. 
different health problems such as respiratory diseases (upper airway inflammation, cough, dyspnea, whistling breath, allergic diseases) $[10,11]$ and gastrointestinal problems (diarrhea) [12].

When evaluating the employees' exposure to microscopic fungi, it is also necessary not only to determine airborne fungi concentrations but also to identify their species composition since their harmfulness to humans varies [13]. Fungal species composition in air samples was described only in several studies with genera Penicillium and Aspergillus often dominating otherwise very broad spectra of detected species $[8,9,13-15]$. These genera contain species able to produce mycotoxins and pose a direct health risk to employees [16]. Even less is known about how fungal concentrations and species composition vary depending on environmental conditions, such as a seasonal variation and time since the start of the work shift. This study aims at evaluating the airborne fungi contamination levels in 2 waste sorting facilities during the working shift in different seasons of the year. Further, we put emphasis on the identification of common and potentially toxigenic species.

\section{MATERIAL AND METHODS}

\section{Sampling sites, sampling design and sample processing}

Sampling of airborne fungi was carried out in 2 plastic waste sorting facilities in the Czech Republic. The samples were taken in the breathing zone (approximately at the height of $1.5 \mathrm{~m}$ ) near to the conveyor belt where employees sort plastic waste. The samples were collected during 2013 and 2014 (October 2013, January 2014, May 2014, and August 2014). In each sampling season, samples of airborne fungi were collected within one work shift. During each work shift (duration $8 \mathrm{~h}$ ), there were performed 10 measurements, the first one before the beginning of the work shift, then every hour during the shift and the last one an hour after the end of the shift. In total, 1920 samples were taken.

During each measurement, air was sampled by means of a 37-mm Filter Holder (BGI Inc., USA) connected with a portable constant-flow Leland Legacy Sample Pump (SKC Ltd., UK). The pump was calibrated to the flow rate of $5 \mathrm{l} / \mathrm{min}$. The sampling period per 1 sample was $24 \mathrm{~min}$. Thus, the amount of sampled air was $120 \mathrm{l}$. Sampling and subsequent processing of samples were performed according to methods described by Černá et al. [17].
Four types of cultivation media with added antibiotics were used for the collection and detection of a broader spectrum of airborne fungi from sampled air: dichloran rose-Bengal chloramphenicol (DRBC), yeast glucose chloramphenicol (YGC), Sabouraud dextrose agar (SDA) supplemented with chloramphenicol (100 mg/l) and malt extract agar (MEA) (Oxoid Ltd., UK) supplemented with chloramphenicol $(100 \mathrm{mg} / \mathrm{l})$. Petri dishes were incubated at $25 \pm 1^{\circ} \mathrm{C}$ for $72 \mathrm{~h}$. After the incubation, colonies of fungi were counted and recalculated as the number of $\mathrm{CFU} / \mathrm{m}^{3}$. All cultivation media were replicated on 6 plates per sample.

\section{Fungal species identification}

Colony-forming units of the fungi from the plates were divided into morphotypes. Representative colonies of each morphotype were selected for the identification. These colonies were concurrently cultivated on 3 cultivation media MEA, Czapek Dox Agar (CZA) and Czapek Yeast Extract Agar (CYA) (HiMedia Laboratoires Pvt. Ltd., India) at $25 \pm 1^{\circ} \mathrm{C}$ for 7 days. Then the fungi were classified to genera or species by using a light microscopy. Identification of fungi was achieved through macro- and microscopic characteristics as described by Ellis and Hesseltine [18], Pitt and Hocking [19] and de Hoog et al. [20].

\section{Statistical analysis}

The data on the concentration of airborne fungi was analyzed by means of hierarchical ANOVA due to the split-plot structure of the dataset with 4 levels. For the final analysis purposes, the response variable, abundance of $\mathrm{CFU} / \mathrm{m}^{3}$ was log-transformed in order to meet the assumption of homogeneity of variance (increasing variance with fitted mean was detected from regression diagnostic graphs of the preliminary analysis). The tested predictors were: season, waste sorting facility, sampling time (both linear and quadratic terms of the considered relationship), cultivation medium and all their interactions. We did not consider interactions of other factors with season since there were only 2 sampling occasions per season. All computations were undertaken in R 3.0.1 (R Core Development Team, Austria) statistical environment under the base installation [21].

The species composition of the detected fungi was analyzed by means of the canonical correspondence analysis (CCA). The dependent variables, i.e., the numbers of the CFU for each fungal species, were logtransformed prior to the analysis since the dataset was 
largely dominated by a few common species, while a multitude of relatively infrequent species was present as well. We tested for differences in fungal species composition among the sampling seasons using the permutation tests with 4999 permutations. A proper number of replicates for testing the effect of sampling season is 8 ( 2 sorting facilities $\times 4$ sampling seasons), which was achieved by applying the hierarchical design with 8 whole plots containing 80 split-plots each and allowing to permute only the whole-plots (see Lepš and Šmilauer [22] for further argumentation). All multivariate analyses were undertaken in Canoco 5.04 (Microcomputer Power Inc., USA) [23].

\section{RESULTS}

\section{Concentrations of airborne fungi}

There was a marginally significant trend of summer and spring samples yielding the highest CFU concentrations (Table 1, Figure 1). The concentrations of airborne fungi ranged $2.1 \times 10^{3}-1.8 \times 10^{6} \mathrm{CFU} / \mathrm{m}^{3}$ in spring, $9.1 \times 10^{3}-$ $9.0 \times 10^{5} \mathrm{CFU} / \mathrm{m}^{3}$ in summer, $2.0 \times 10^{2}-4.2 \times 10^{5} \mathrm{CFU} / \mathrm{m}^{3}$ in autumn and $2.7 \times 10^{3}-2.9 \times 10^{5} \mathrm{CFU} / \mathrm{m}^{3}$ in winter. Contrary to our expectations, the differences in airborne fungi concentrations among the 2 facilities were not of particular importance (Table 2).

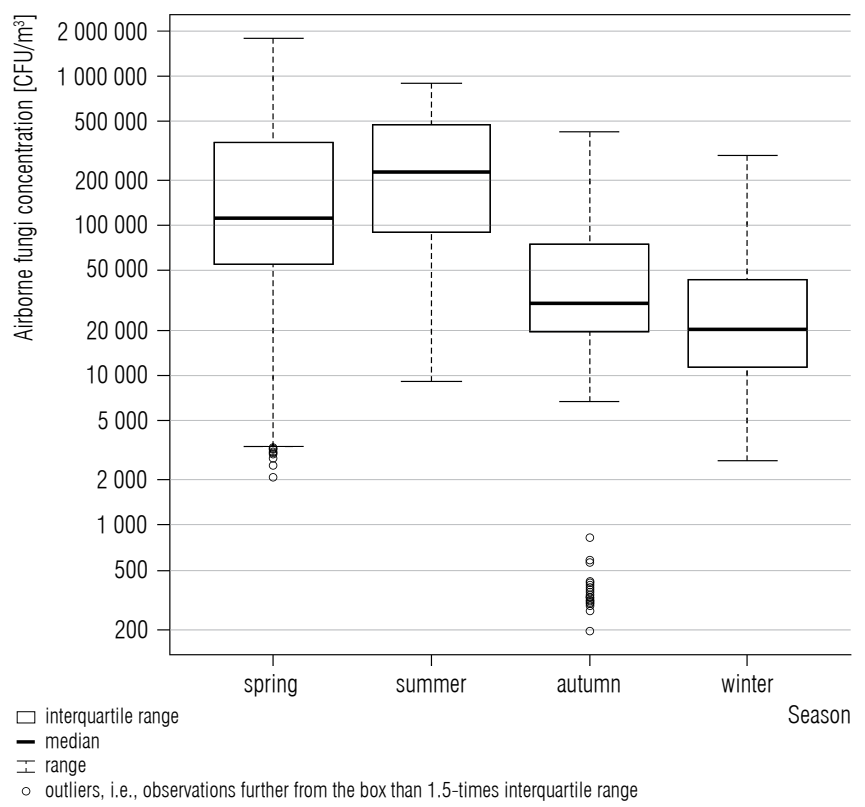

CFU - colony-forming units.

Fig. 1. Airborne fungi concentration in the studied plastic waste sorting facilities in the Czech Republic, 2013-2014, by season

The results of the split-plot ANOVA indicated that the hour of sampling (both linear and quadratic term) and the type of cultivation medium were the only drivers of the detected CFU concentrations (Table 2). The

Table 1. Airborne fungi in the studied plastic waste sorting facilities in the Czech Republic, 2013-2014, by season

\begin{tabular}{|c|c|c|c|c|}
\hline \multirow{2}{*}{$\begin{array}{c}\text { Season } \\
\text { and waste sorting facility }\end{array}$} & \multicolumn{4}{|c|}{$\begin{array}{l}\text { Airborne fungi } \\
{\left[\mathrm{CFU} / \mathrm{m}^{3}\right]}\end{array}$} \\
\hline & M & SD & back-transformed M & $95 \% \mathrm{CI}$ \\
\hline A & $1.1 \times 10^{5}$ & $8.6 \times 10^{4}$ & $9.4 \times 10^{4}$ & $8.7 \times 10^{4}-1.0 \times 10^{5}$ \\
\hline A & $3.4 \times 10^{5}$ & $2.6 \times 10^{5}$ & $2.3 \times 10^{5}$ & $2.0 \times 10^{5}-2.6 \times 10^{5}$ \\
\hline $\mathrm{B}$ & $2.4 \times 10^{5}$ & $2.1 \times 10^{5}$ & $1.5 \times 10^{5}$ & $1.3 \times 10^{5}-1.7 \times 10^{5}$ \\
\hline \multicolumn{5}{|l|}{ Autumn } \\
\hline A & $5.0 \times 10^{4}$ & $6.2 \times 10^{4}$ & $2.5 \times 10^{4}$ & $2.2 \times 10^{4}-2.9 \times 10^{4}$ \\
\hline $\mathrm{B}$ & $2.3 \times 10^{4}$ & $1.6 \times 10^{4}$ & $1.8 \times 10^{4}$ & $1.7 \times 10^{4}-2.0 \times 10^{4}$ \\
\hline
\end{tabular}

CFU - colony-forming units, M - mean, SD - standard deviation, back-transformed M - mean on the logarithmic scale (the scale of measurements, where approximation by normal distribution and data analysis is possible), which was back-transformed to the original scale, $95 \% \mathrm{CI}-95 \%$ confidence interval of the back-transformed mean (the asymmetry of confidence intervals on the original scale corresponds to the skewness of the response variable). 
initial increase and later stagnation of the CFU concen- On the other hand, effects of the cultivation medium tration during the progressing working shift (Figure 2) were completely marginal given the amount of variation explained together $20.8 \%$ of the total variation (Table 2). it explained. The highest numbers of the detected CFU

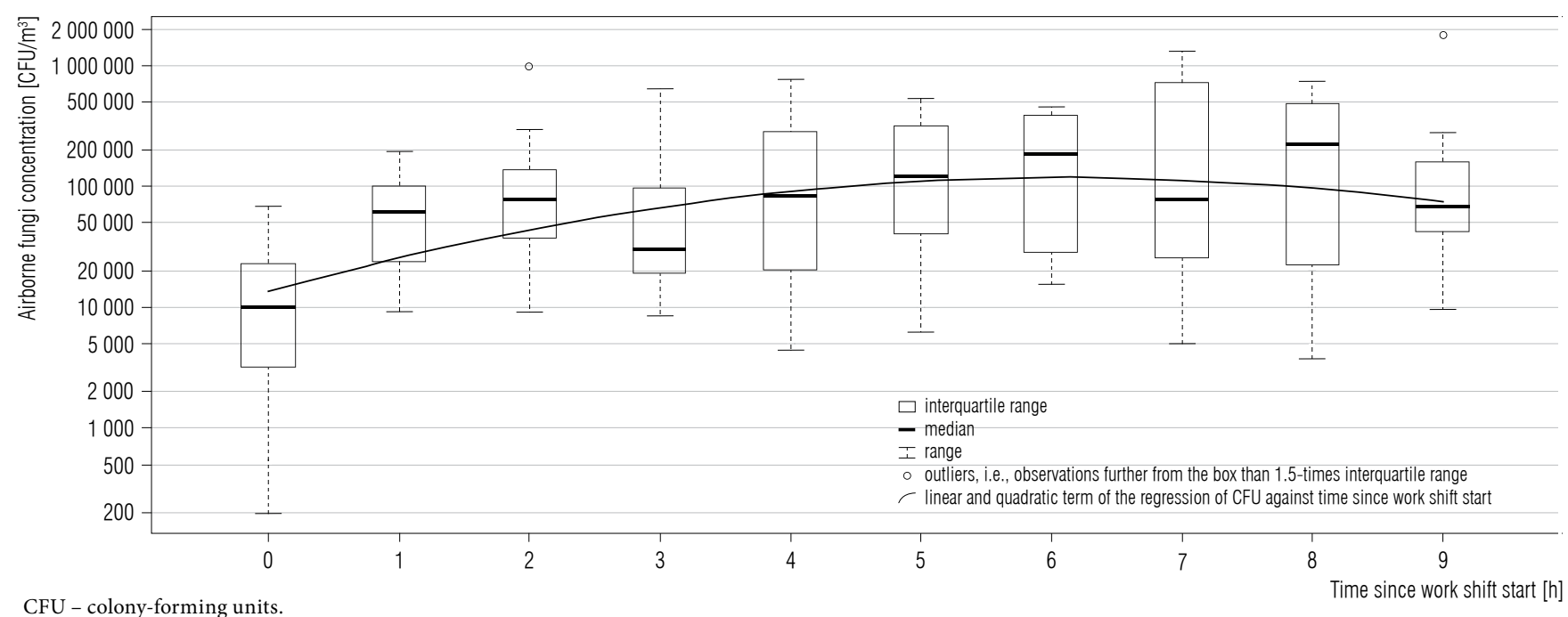

Fig. 2. Airborne fungi concentration in the studied plastic waste sorting facilities in the Czech Republic, 2013-2014, by time elapsed since the work shift start

Table 2. Hierarchical ANOVA of log-number of colony-forming units (CFU) of airborne fungi in the studied plastic waste sorting facilities in the Czech Republic, 2013-2014

\begin{tabular}{|c|c|c|c|c|}
\hline Predictor & $\mathrm{df}$ & $\begin{array}{c}\text { Explained } \\
\text { variation* } \\
{[\%]}\end{array}$ & Sum of squares & $\mathrm{p}$ \\
\hline \multicolumn{5}{|l|}{ Variation among seasons and factories } \\
\hline season & 3 & 35.4 & 1547.9 & 0.088 \\
\hline factory identity & 1 & 0.9 & 39.9 & n.s. \\
\hline residual variation & 3 & 5.9 & 259.9 & \\
\hline \multicolumn{5}{|c|}{ Variation among hours within sampler type, factory and season } \\
\hline hour of sampling (linear) & 1 & 13.1 & 574.0 & $<0.001$ \\
\hline hour of sampling (quadratic) & 1 & 7.7 & 335.8 & $<0.001$ \\
\hline factory $\times$ hour (linear) & 1 & 0.7 & 28.5 & n.s. \\
\hline factory $\times$ hour (quadratic) & 1 & 0.6 & 26.1 & n.s. \\
\hline residual variation & 68 & 33.8 & 1476.3 & \\
\hline \multicolumn{5}{|c|}{ Variation among mediums within hour, sampler type, factory and season } \\
\hline medium & 3 & 0.1 & 6.3 & $<0.001$ \\
\hline factory $\times$ medium & 3 & 0.0 & 0.4 & n.s. \\
\hline hour $($ linear $) \times$ medium & 3 & 0.0 & 0.9 & n.s. \\
\hline hour (quadratic) $\times$ medium & 3 & 0.0 & 0.2 & n.s. \\
\hline factory $\times$ hour $($ linear $) \times$ medium & 3 & 0.0 & 0.4 & n.s. \\
\hline factory $\times$ hour $($ quadratic $) \times$ medium & 3 & 0.0 & 0.1 & n.s. \\
\hline residual variation & 222 & 0.9 & 37.5 & \\
\hline \multicolumn{5}{|c|}{ Variation among dishes within medium, hour, sampler type, factory and season } \\
\hline residual variation & 1600 & 0.8 & 34.4 & \\
\hline
\end{tabular}

df - degrees of freedom, n.s. - not statistically significant.

* Amount of total variation (i.e., at all hierarchical levels) explained. 
of airborne fungi within all measurements were detected on the DRBC cultivation medium as compared to the other cultivation media (SDA, MEA and YGC).

\section{Species composition of fungi}

\section{cultivated from samples}

The exploration of the multivariate data on the fungal species composition indicated that the effect of the season on the species composition of fungi cultivated from samples may only be expected. The canonical correspondence analysis indicated that the season identity explained $11.4 \%$ of the variance in the species composition of fungi ( $\mathrm{p}=0.010$ ) (Figure 3 ).

The dominating airborne fungi detected in this study belonged to the genus Penicillium (75.1\% of all cultivated fungi) but there was a turnover of particular species among seasons. The next most frequently detected genera were in the decreasing order: Aspergillus (11.3\%), Acremonium (3.1\%), Paecilomyces (2.6\%),

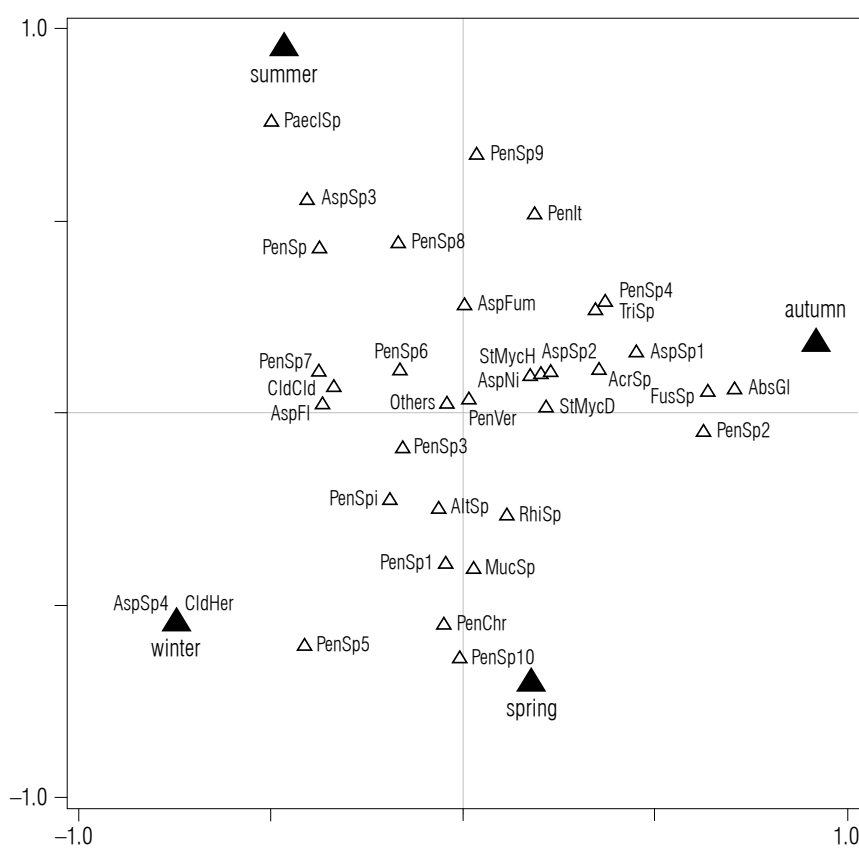

AbsGl - Absidia glauca, AcrSp - Acremonium sp., AltSp - Alternaria sp., AspFl Aspergillus flavus, AspFum - Aspergillus fumigatus, AspNi - Aspergillus niger, AspSp1-4 - Aspergillus sp. 1-4, CldCld - Cladosporium cladosporioides s.l., CldHer Cladosporium herbarum s.l., FusSp - Fusarium sp., MucSp - Mucor sp., PaeclSp Paecilomyces sp., PenChr - Penicillium chrysogenum, PenIt - Penicillium italicum, PenSpi - Penicillium spinulosum, PenSp1-11 - Penicillium sp. 1-11, PenVer - Penicillium verrucosum, RhiSp - Rhizopus sp., StMycD - dark sterile mycelium, StMycH hyaline sterile mycelium, TriSp - Trichoderma sp., others - unidentified fungi.

* First and second canonical axes explain $5.1 \%$ and $4.6 \%$ of variation respectively and account for $85.3 \%$ of the total $11.4 \%$ of variation explained by sampling season.

Fig. 3. Canonical correspondence analysis (CCA) of fungi species composition (log-transformed counts of colony-forming units (CFU)) in the studied plastic waste sorting facilities in the Czech Republic, 2013-2014*
Cladosporium (1.9\%), Rhizopus (1.1\%), Mucor (1.0\%), Absidia (0.5\%), Trichoderma (0.4\%), Alternaria (0.1\%) and Fusarium (0.1\%). The highest diversity of fungal species was observed in the samples taken in autumn. The presence of potentially toxigenic fungi Aspergillus niger, A. flavus, A. fumigatus and Penicillium chrysogenum was recorded in all seasons in both facilities.

Winter and summer samples were specific by unique abundant fungi species (winter - Rhizopus sp., P. chrysogenum, Penicillium sp. 1, Penicillium sp. 5, Penicillium sp. 6; summer - Paecilomyces sp., Cladosporium cladosporioides s. 1., Penicillium sp. 7, Penicillium sp. 8, Penicillium sp. 11), while autumn and spring samples hardly contained these species (Figure 4).

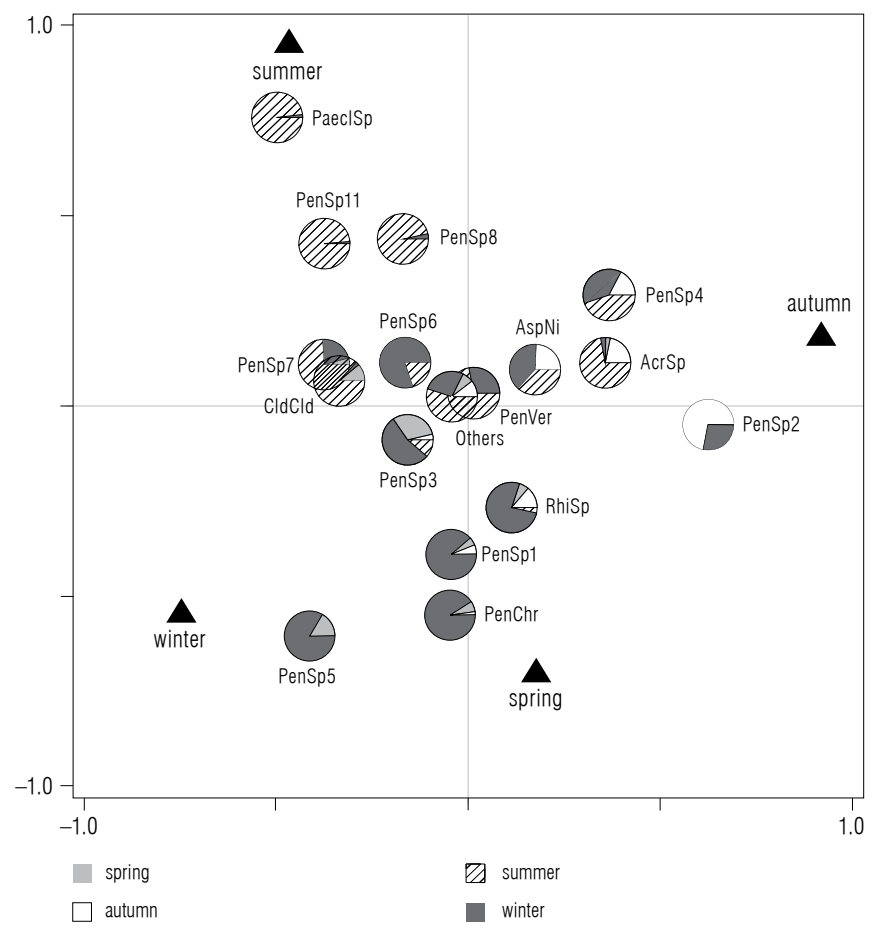

Abbreviations as in Figure 3.

* The pie charts depict proportions of detected CFUs of a given fungal species in a given season.

Fig. 4. Canonical correspondence analysis (CCA) of composition of fungi species occurring in more than $5 \%$ of samples in the studied plastic waste sorting facilities in the Czech Republic, 2013-2014*

\section{DISCUSSION}

\section{Concentrations of airborne fungi}

Our results indicate that the seasonal and diurnal variations in concentrations of airborne fungi need to be taken into account when assessing the load rate of employees in the waste sorting facilities. Their importance 
is comparable to other drivers of load rates of employees such as the sorting technology (the open conveyor belt, ventilation system, accumulation of waste in the plant, frequency and quality of cleaning) $[7,14]$ and the quality of the input material (i.e., its contamination by microscopic fungi) [8].

The overall measured exposure of employees to airborne fungi was more or less comparable to that reported in studies from similar waste treatment facilities $[4,6-9,14,15,24]$. Nevertheless, comparing the results of these studies is complicated due to the different sampling methods, sample processing applied and other sources of variation (see Černá et al. [17], Eduarda and Heederik [25] for discussion of the problem). However, the concentrations of airborne fungi in this study were clearly higher (2-4 orders of magnitude) to those found in other indoor environments [26-29]. It points to the potential health risk for employees.

There was a trend of highest concentrations of airborne fungi being measured in summer and spring, while the lowest ones are reported to occur in winter. On the contrary, Rahkonen [6] measured the highest concentration of airborne fungi in autumn and then in spring and summer. Differences in the measured concentrations may point to the varying microclimate conditions (temperature, relative air humidity) inside the sorting facilities during the year [30]. Higher temperature and air humidity may cause an increased microbial activity and thus a higher concentration of airborne fungi [31]. However, release of fungal particles into ambient air also depends on fungal genus as well as air velocity [32].

The diurnal variation in the airborne fungi concentrations showed a quite expectable pattern, i.e., gradual increase since the start of the working shift, which reaches a plateau after ca $6-7 \mathrm{~h}$ of working, however notable is the difference of the order of magnitude between the lowest and highest predicted values. The observed trend could be associated with the increasing amount of sorted waste during the work shift and depletion of its supply for sorting towards the end of the work shift.

\section{Species composition \\ of fungi cultivated from samples}

The species composition of airborne fungi cultivated from samples was similar to that referred in studies from similar facilities $[8,9,13,14,24]$, where the dominating species were from the genera Penicillium and Aspergillus with their proportions varying among studies.
In our study, the dominating fungi were those of the genus Penicillium (75.1\%) followed by Aspergillus (11.3\%). Lehtinen et al. (2013) [9] reported the identification of the genus Penicillium in $93 \%$ of all the cultivated fungi. On the other hand, Viegas et al. (2014) [13] predominantly identified the genus Aspergillus, the genus Penicillium was not determined. Tolvanen et al. (1999) [24] determined the genus Aspergillus in $40 \%$ and the genus Penicillium in $44 \%$ of all the cultivated fungi.

In our study, species composition of airborne fungi in waste sorting facilities changed during the year (Figure 3). The species composition may be influenced by microscopic fungi from waste as well as airborne fungi from the outside environment, that penetrate through doors and windows. The most frequently isolated fungi from outside environment are those of the genera Penicillium, Aspergillus, Cladosporium and Alternaria [33-35]. Genera Penicillium and Aspergillus dominated in this study in all seasons. On the other hand, the next most frequently detected genera Acremonium, Paecilomyces, Cladosporium, Rhizopus predominated only in one season (Figure 4). Larsen and Gravesen [33] recorded the same seasonal patterns of genera Penicillium, Aspergillus and Cladosporium in the long-term study which was conducted in an outdoor environment.

In both waste sorting facilities, the potentially mycotoxins-producing fungi $A$. niger, A. fumigatus, A. flavus and $P$. chrysogenum were detected in all seasons and $A$. niger was even the second most frequently isolated fungal species in all samples. These fungal species were also detected in air samples from waste sorting facilities in several other studies $[7,8,13]$. However, only a limited number of studies focus on employees' exposure to mycotoxins in waste sorting facilities. Viegas et al. (2015) [36] found high aflatoxin B1 values (produced by A. flavus) in blood samples collected from employees of waste sorting facility. This mycotoxin is considered by different International Agencies as a genotoxic and potent hepatocarcinogen. Moreover, other mycotoxins are probably present in the working environment of waste sorting facilities and this aspect should be taken into consideration due to their possible synergistic reactions [37]. However, fungi are still used as an indirect indicator of mycotoxins' presence in working environments [38].

Some fungi detected in our study belong to the genera Alternaria, Aspergillus, Cladosporium, Fusarium and Penicillium is assumed to elicit allergic inflammatory reactions and different human infections $[27,39,40]$. However, there is a little information on clinically sig- 
nificant concentrations of these airborne fungi necessary to cause health problems. Bagni et al. [41] reported that $1 \times 10^{2} \mathrm{CFU} / \mathrm{m}^{3}$ of the genus Alternaria and $3 \times 10^{3} \mathrm{CFU} / \mathrm{m}^{3}$ of the genus Cladosporium led to allergic reactions. These concentrations were exceeded in our study in both facilities in all seasons.

Several studies showed a relationship between the working activities in waste management and the presence of various health problems in employees, such as respiratory diseases $[1,2,10]$, gastrointestinal problems [1,2] and metabolic syndrome [3]. However, a direct link to fungi cannot be drawn since employees in waste management are exposed besides to fungi also to dust, bacteria and other metabolites $[6,9,14,15]$. Nevertheless, this aspect should be taken into consideration for the risk assessment process due to possible synergistic effects on human health.

Based upon our results, we recommend the use of the protective equipment (thick rubber gloves, respiratory mask, working clothes) by employees and the introduction of preventive measures in working environment of waste sorting facilities. We especially recommend to raise employees' awareness of health risks that they may be exposed to and to disseminate information about preventive methods applicable during the work. Furthermore, adequate ventilation system in the working environment should be installed, frequency and quality of the wet cleaning phase should be increased and regular and detailed medical examinations of employees should be introduced. These recommendations could lead to minimizing of risks to employees' health in waste sorting facilities.

\section{CONCLUSIONS}

We performed a general evaluation of the occupational exposure of workers employed in the plastic sorting plant to airborne fungi during the work shift in four seasons of the year. Overall, high concentrations of airborne fungi and the presence of potentially toxigenic fungal species in the work environment were detected in all measurements with some of the harmful taxa (e.g., Aspergillus niger) being among the most frequently species. A trend of higher airborne fungi concentrations was found in summer and spring when compared to autumn and winter. The lowest airborne fungi concentrations were found at the beginning of the work shift followed by the quick increase reaching a plateau (sometimes followed by a slight decrease towards the end of the shift). This study shows that the sorting plant is the working environment with increased concentrations of airborne fungi and corresponding preventive measures need to be taken in order to decrease the employees' exposure to harmful agents.

\section{ACKNOWLEDGMENTS}

We thank Adam Perný for technical help.

\section{REFERENCES}

1. Marth E, Reinthaler FF, Schaffler K, Jelovcan S, Haselbacher S, Eibel U, et al. Occupational health risks to employees of waste treatment facilities. Ann Agric Environ Med. 1997;4:143-7.

2. Krajewski JA, Tarkowski S, Cyprowski M. [Hazardous health effects in communal waste collection and disposal workers]. Med Pr. 1999;51(2):159-72. Polish.

3. Eker HH, Bayraktarli RY, Işsever H, Ulaş T, Erelel M, Eser A, et al. Metabolic syndrome in collection and disposal of solid waste sector. Int J Occup Med Environ Health. 2012;25(1):14-21, https://doi.org/10.2478/s13382012-0004-z.

4. Park DU, Ryu SH, Kim SB, Yoon CS. An assessment of dust, endotoxin, and microorganism exposure during waste collection and sorting. J Air Waste Manag Assoc. 2011;61(4):461-8, https://doi.org/10.3155/1047-3289.61.4.461.

5. Kozajda A, Sowiak M, Piotrowska M, SzadkowskaStańczyk I. [Waste sorting plants - recognition of exposure to biological agents (moulds)]. Med Pr. 2009;60(6): 483-90. Polish.

6. Rahkonen P. Airborne contaminants at waste treatment plants. Waste Manag Res. 1992;10(5):411-21, https://doi. org/10.1016/0734-242X(92)90115-2.

7. Reinthaler FF, Haas D, Feierl G, Schlacher R, Pichler-Semmelrock FP, Köck M, et al. Comparative investigations of airborne culturable microorganisms in selected waste treatment facilities and in neighbouring residential areas. Zentralbl Hyg Umweltmed. 1999;202(1):1-17, https://doi. org/10.1016/S0934-8859(99)80046-7.

8. Würtz H, Breum NO. Exposure to microorganisms during manual sorting of recyclable paper of different quality. Ann Agric Environ Med. 1997;4:129-35.

9. Lehtinen J, Tolvanen O, Nivukoski U, Veijanen A, Hänninen K. Occupational hygiene in terms of volatile organic compounds (VOCs) and bioaerosol at two solid waste management plants in Finland. Waste Manag. 2013;33(4): 964-73, https://doi.org/10.1016/j.wasman.2012.11.010.

10. Kozajda A, Szadkowska-Stańczyk I. [Selected health complains, allergic diseases, hygiene behaviors and knowledge 
of biohazards among workers of waste sorting plants]. Med Pr. 2009;60(6):491-9. Polish.

11. Heldal KK, Halstensen AS, Thorn J, Djupesland P, Wouters I, Eduard W, et al. Upper airway inflammation in waste handlers exposed to bioaerosols. Occup Environ Med. 2003;60(6):444-50, https://doi.org/10.1136/oem.60.6.444.

12. Ivens UI, Breum NO, Ebbehøj N, Nielsen BH, Poulsen OM, Würtz H. Exposure-response relationship between gastrointestinal problems among waste collectors and bioaerosol exposure. Scand J Work Environ Health. 1999; 25(3):238-45, https://doi.org/10.5271/sjweh.430.

13. Viegas C, Gomes AQ, Abegão J, Sabino R, Graça T, Viegas S. Assessment of fungal contamination in waste sorting and incineration - Case study in Portugal. J Toxicol Environ Health A. 2014;77:57-68, https://doi.org/10.1080/ 15287394.2014.865583.

14. Kiviranta H, Tuomainen A, Reiman M, Laitinen S, Nevalainen A, Liesivuori J. Exposure to airborne microorganisms and volatile organic compounds in different types of waste handling. Ann Agric Environ Med. 1999; 6(1):39-44.

15. Tolvanen OK, Hänninen KI. Mechanical-biological waste treatment and the associated occupational hygiene in Finland. Waste Manag. 2006;26(10):1119-25, https://doi. org/10.1016/j.wasman.2005.07.020.

16. Pitt JI. The current role of Aspergillus and Penicillium in human and animal health. J Med Vet Mycol. 1994;32 Suppl1:17-32,https://doi.org/10.1080/02681219480000701.

17. Černá K, Wittlingerová Z, Zimová M, Janovský Z. Methods of sampling airborne fungi in working environments of waste treatment facilities. Int J Occup Med Environ Health. 2016;29(3):493-502, https://doi.org/10.13075/ijomeh.1896.00568.

18. Ellis JJ, Hesseltine CW. The genus Absidia: Globose-spored species. Mycologia. 1965;57(2):222-35.

19. Pitt JI, Hocking AD. Fungi and food spoilage. 2nd ed. London: Blackie Academic and Professional; 1997, https:// doi.org/10.1007/978-1-4615-6391-4.

20. De Hoog GS, Guarro J, Gené J, Figueras MJ. Atlas of clinical fungi. 2nd ed. Utrecht: Centraalbureau voor Schimmelcultures; 2000, https://doi.org/10.1023/A:1013183715057.

21. The R Project for Statistical Computing [Internet]. Vienna: R Foundation; 2013 [cited 2014 Jun 6]. Available from: https://www.r-project.org.

22. Lepš J, Šmilauer P. Multivariate analysis of ecological data using CANOCO. Cambridge: Cambridge University Press; 2003.

23. Braak CJF, Šmilauer P. CANOCO reference manual and user's guide: Software for ordination (version 5.0). Ithaca: Microcomputer Power; 2012.
24. Tolvanen OK, Hänninen KI, Lappi SH, Rantala P. Occupational hygiene at a dry waste treatment plant in Finland. In: Proceedings of the 7th North American Wasteto-Energy Conference; 1999 May 17-19; Tampa (FL), USA. 1999. p. 163-72.

25. Eduarda W, Heederik D. Methods for quantitative assessment of airborne levels of noninfectious microorganisms in highly contaminated work environments. Am Ind Hyg Assoc J. 1998;59(2):113-27, https://doi.org/ 10.1080/15428119891010370.

26. Górny RL, Krysińska-Traczyk E. Quantitative and qualitative structure of fungal bioaerosol in human dwellings of Katowice province, Poland. In: International Academy of Indoor Air Sciences, International Society of Indoor Air Quality and Climate. Indoor Air 99: Proceedings of the 8th International Conference on Indoor Air Quality and Climate; 1999 Aug 8-13; Edinburgh, Scotland, UK. Peterborough: Construction Research Communications; 1999. p. 873-78.

27. Fischer G, Dott W. Relevance of airborne fungi and their secondary metabolites for environmental, occupational and indoor hygiene. Arch Microbiol. 2003;179:75-82, https://doi.org/10.1007/s00203-002-0495-2.

28. Klánová K. The concentrations of mixed populations of fungi in indoor air: Rooms with and without mould problems; rooms with and without health complaints. Cent Eur J Public Health. 2000;8(1):59-61.

29. Pastuszka JS, Paw UKT, Lis DO, Wlazło A, Ulfig K. Bacterial and fungal aerosol in indoor environment in Upper Silesia, Poland. Atmos Environ. 2000;34(22):3833-42, https://doi.org/10.1016/S1352-2310(99)00527-0.

30. Nielsen KF, Holm G, Uttrup LP, Nielsen PA. Mould growth on building materials under low water activities. Influence of humidity and temperature on fungal growth and secondary metabolism. Int Biodeterior Biodegradation. 2004;54(4):325-36, https://doi.org/10.1016/ j.ibiod.2004.05.002.

31. Shelton BG, Kirkland KH, Flanders WD, Morris GK. Profiles of airborne fungi in buildings and outdoor environments in the United States. Appl Environ Microbiol. 2002;68(4):1743-53.

32. Pasanen A-L, Pasanen P, Jantunen MJ, Kalliokoski P. Significance of air humidity and air velocity for fungal spore release into the air. Atmos Environ A. 1991;25(2):459-62, https://doi.org/10.1016/0960-1686(91)90316-Y.

33. Larsen L, Gravesen S. Seasonal variation of outdoor airborne viable microfungi in Copenhagen, Denmark. Grana. 1991;30(2):467-71, https://doi.org/10.1080/00173139109432011.

34. De Ana SG, Torres-Rodríguez JM, Ramirez EA, Garcia SM, Belmonte-Soler J. Seasonal distribution of Alter- 
naria, Aspergillus, Cladosporium and Penicillium species isolated in homes of fungal allergic patients. J Investig Allergol Clin Immunol. 2006;16(6):357-63.

35. Medrela-Kuder E. Seasonal variations in the occurrence of culturable airborne fungi in outdoor and indoor air in Cracow. Int Biodeterior Biodegradation. 2003;52(4):203-5, https://doi.org/10.1016/S0964-8305(02)00167-1.

36. Viegas S, Veiga L, Figueiredo P, Almeida A, Carolino E, Viegas C. Assessment of workers' exposure to aflatoxin B1 in a Portuguese waste industry. Ann Occup Hyg. 2015; 59(2):173-81, https://doi.org/10.1093/annhyg/meu082.

37. Speijers GJA, Speijers MHM. Combined toxic effects of mycotoxins. Toxicol Lett. 2004;153:91-8, https://doi.org/ 10.1016/j.toxlet.2004.04.046.
38. Thrane U, Adler A, Clasen P-E, Galvano F, Langseth W, Lew $\mathrm{H}$, et al. Diversity in metabolite production by Fusarium langsethiae, Fusarium poae, and Fusarium sporotrichioides. Int J Food Microbiol. 2004;95(3):257-66, https://doi. org/10.1016/j.ijfoodmicro.2003.12.005.

39. Horner WE, Helbling A, Salvaggio JE, Lehrer SB. Fungal allergens. Clin Microbiol Rev. 1995;8(2):161-79.

40. Ozcan M, Ozcan KM, Karaarslan A, Karaarslan F. Concomitant otomycosis and dermatomycoses: A clinical and microbiological study. Eur Arch Otorhinolaryngol. 2003; 260(1):24-7, https://doi.org/10.1007/s00405-002-0514-6.

41. Bagni N, Davies RR, Mallea M, Nolard N, Spireksma FT, Stix E. [Spore concentration in cities of the European Economic Community. II. Spores of Cladosporium and Alternaria]. Acta Allergol. 1977;32(2):118-38. German.

This work is available in Open Access model and licensed under a Creative Commons Attribution-NonCommercial 3.0 Poland License - http://creativecommons.org/licenses/by-nc/3.0/pl/deed.en. 